\title{
Tensile Shear Strength Characteristics for Adhesively Single-lap Joints Composed of Quasi-isotropic Laminated CFRPs and Aluminum Alloy
}

\author{
Jyo Shimura $^{\text {a, }}$, Mutsumi Miyagawa ${ }^{\text {b }}$, Shigeru Kurosaki ${ }^{c}$ \\ aDepartment of Mechanical and Electrical Engineering, Suwa University of Science, \\ 5000-1 Toyohira, Chino-shi, Nagano, 391-0292, Japan \\ ${ }^{b}$ Monozukuri Engineering Department, Tokyo Metropolitan College of Industrial Technology, \\ 8-17-1 Minamisenjyu, Arakawa-ku, Tokyo, 116-8523, Japan \\ ${ }^{c}$ Former professor at National Institute of Technology, Tokyo College, \\ 1220-2 Kunugida-machi, Hachioji-shi, Tokyo, 193-0997, Japan \\ *Corresponding Author: jyo@rs.sus.ac.jp
}

\begin{abstract}
The purpose of this study is to clarify the strength characteristics of the single-lap joints in which quasi-isotropic laminated CFRPs and an aluminum alloy are adhesively bonded and subjected to tensile shear load. Stress distribution at the adhesive layer was investigated by using three-dimensional finite element stress analysis, and joint strength was measured by tensile shear test. In addition, the effects of the lamination configuration of the quasi-isotropic laminated CFRPs on the adhesive layer stress distribution and tensile shear strength were examined. According to the analysis results, it was suggested that if the fiber direction near the adhesive layer was inclined, an asymmetrical stress distribution would occur. From the experimental results, it was confirmed that the tensile shear strength tended to increase as the fiber orientation angle near the adhesive layer approached the longitudinal direction of the joint.
\end{abstract}

Keywords: Adhesive bonding, Quasi-isotropic laminated CFRPs, Single-lap joint, Tensile shear strength

\section{Introduction}

Carbon fiber reinforced plastic, that is, CFRP, is attracting attention as a structural material with excellent mechanical properties such as light weight, high elastic modulus, and high strength. Due to the increasing demand for CFRP and the promotion of multi-materials for automobile bodies, adhesive bonding between conventional structural materials and CFRP has become an important technology, and research is being carried out in various fields. Machado et al. ${ }^{(1)}$ investigated the fracture of the adhesive layer under quasi-static and dynamic conditions of the adhesively bonded single-lap joints using CFRP and aluminum alloy as an adherend by finite element analysis using the Cohesive zone model. Jairaja et al. ${ }^{(2)}$ clarified the joint strength when brittle adhesives, ductile adhesives, and both adhesives (Apply brittle adhesive to the center of the adhesive layer and ductile adhesive to both sides) were applied to the single-lap joints composed of CFRP and aluminum alloy by digital image correlation method and finite element analysis. Elena M. Moya-Sanz et al. ${ }^{(3)}$ is developed a finite element model to simulate the influence of different geometrical parameters (adherend recessing and chamfering of the adherends and adhesive) on the behaviour of a laminate composite single-lap joint subjected to uniaxial tensile load, considering only cohesive failure. Sunada et al. ${ }^{(4)}$ investigated the effect of the laminated structure of CFRP on the strength characteristics of the adhesively joint with the CFRP orthogonal laminated plate as the adherend. The above is a part of the past research on adhesive bonding of dissimilar materials using CFRP, but it seems that there are few studies ${ }^{(5-7)}$ on adhesive bonded joints using the quasi-isotropic laminated CFRPs (Where, we named them "Qi-CFRPs") as an adherend. Therefore, in this study, the stress distribution at the adhesive layer and the joint strength characteristics when tensile shear acts on the joints in which the Qi-CFRPs and an aluminum alloy are adhesively joined were 
investigated by three-dimensional finite element stress analysis and tensile shear test. In addition, the effect of the configurations of the Qi-CFRPs on the tensile shear strength of the joint was investigated.

\section{Finite element analysis}

\subsection{Joint geometry and Constituent materials}

In this study, the single-lap joint shown in Fig. 1 was set as the specimen configuration. The dimensions and shape of each part other than the overlap length $(25 \mathrm{~mm})$ were conformed to JIS standards. The Qi-CFRPs and aluminum alloy A6063-T5 (hereinafter referred to as A6063) were used as the adherend materials for the joints. In addition, A Qi-CFRP is composed of 8 layers, and 4 types of Qi-CFRP (Laminate A, B, C, D) with different laminated structures shown in Fig. 2 were used. The $x$-axis direction in Fig. 2 corresponds to the longitudinal direction of the joint. For example, in the case of Laminate A, the fiber direction is $0,45,-45,90^{\circ}$ from the outer layer to the
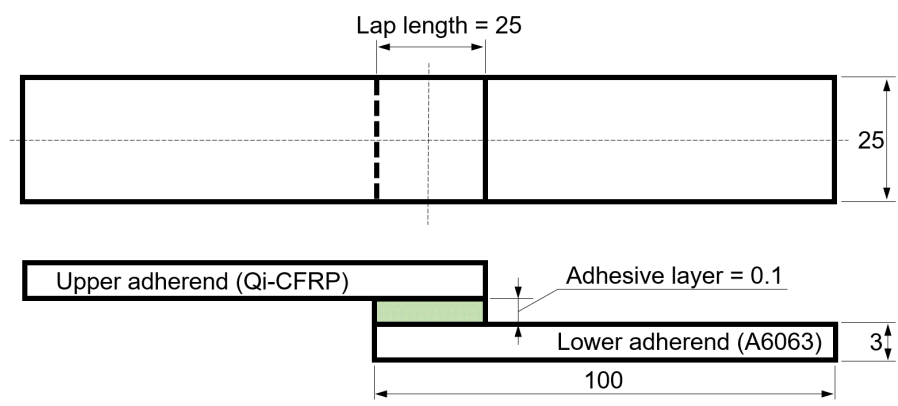

Fig. 1. Dimension and geometry of joint specimen.

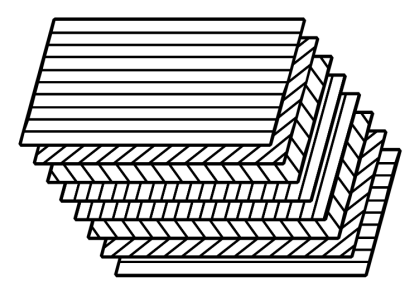

$[0 / 45 /-45 / 90]_{\mathrm{S}}$

(a) Laminate A

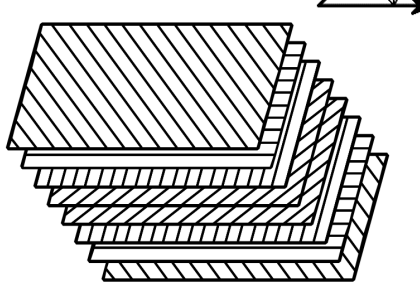

$[-45 / 0 / 90 / 45]_{S}$

(c) Laminate $\mathrm{C}$

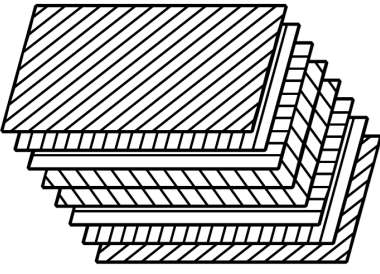

$[45 / 90 / 0 /-45]_{\mathrm{s}}$

(b) Laminate B

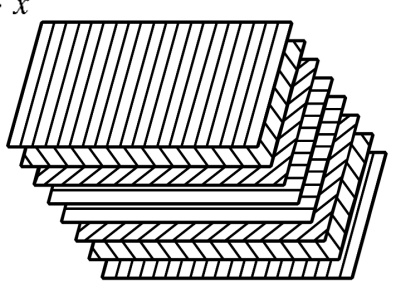

$[90 /-45 / 45 / 0]_{\mathrm{S}}$

(d) Laminate D
Fig. 2. Lay-up patterns of quasi-isotropic CFRP laminates
Table 1. Material properties of adherend and adhesive

\begin{tabular}{|c|c|c|c|c|}
\hline \multirow{2}{*}{ Material } & \multicolumn{2}{|c|}{ Young's modulus [GPa] } & \multicolumn{2}{c|}{ Poisson's ratio } \\
\cline { 2 - 5 } & $E_{x}$ & $E_{y}=E_{z}$ & $v_{x y}=v_{x z}$ & $v_{y z}$ \\
\hline Qi-CFRP & 115 & 7.6 & 0.35 & 0.02 \\
\hline A6063 & \multicolumn{2}{|c|}{70.31} & \multicolumn{2}{c|}{0.33} \\
\hline SW1838 B/A & \multicolumn{2}{|c|}{3.40} & \multicolumn{2}{c|}{0.39} \\
\hline
\end{tabular}

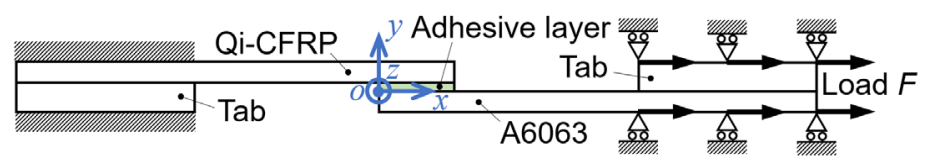

Fig. 3. Model for analysis

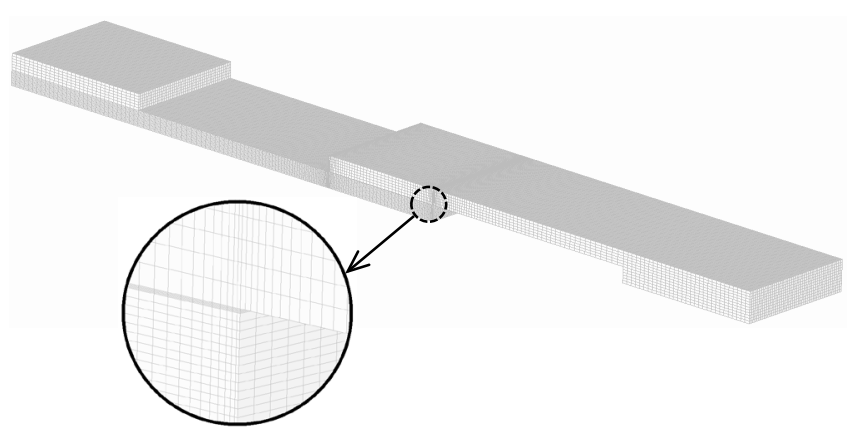

Fig. 4. An example of mesh division used in FEM

4th layer, and the laminated structure becomes symmetrical thereafter. A6063 and the Qi-CFRPs are adhesively bonded using an epoxy structural adhesive (Scotch-Weld 1838B/A, 3M Japan Ltd.). Table 1 shows the properties of these materials. From now on, the joints composed of A6063 and the Qi-CFRPs will be referred to as Laminate A/A6063, Laminate B/A6063, Laminate C/A6063, and Laminate D/ A6063, respectively.

\subsection{Analytical model and Boundary conditions}

In order to examine the relationship between the laminated structures of the Qi-CFRPs and the joint strengths, the stress distributions when the joints subjected to tensile shear loads were investigated by FEM. The FEM software used in this study is Femap with NX Nastran (Ver.11.1.2). An FEM model was created based on the analytical model shown in Fig. 3, which corresponds to the dimensions and shape of the joint specimen shown in Fig. 1. The coordinate system defined the longitudinal direction of the joint as the $x$-axis, the thickness direction as the $y$-axis, and the width direction as the $z$-axis. The material property values in Table 1 were given to each element of the adhesive layer and the adherend, and the fixed conditions were applied to their interfaces. Hexahedron primary elements were used for mesh division, and the longitudinal and width directions of the overlapped part were divided 


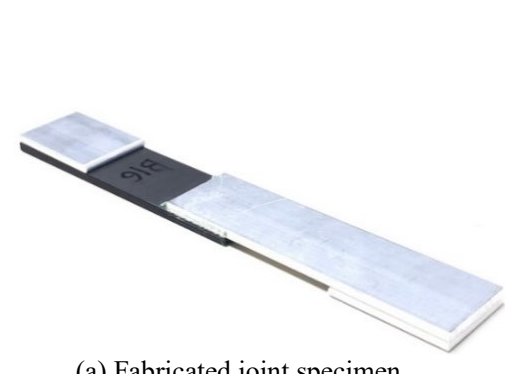

(a) Fabricated joint specimen

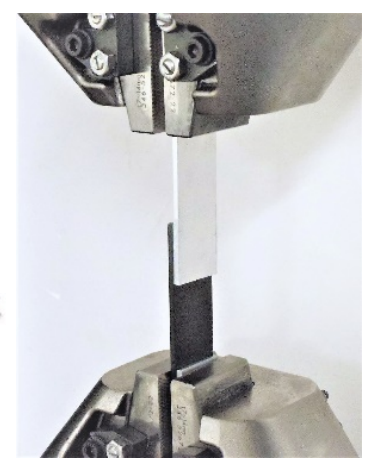

(b) Joint specimen fitted on test machine

Fig. 5. Experimental setup of tensile shear test

into 50, the Qi-CFRPs were divided into 2 in the thickness direction for each layer, and the adhesive layer was divided into 5 in the thickness direction. Fig. 4 shows an example of mesh division. As for the boundary conditions, in consideration of the tensile shear test status of the joint, the upper and lower surfaces of the left grip part in Fig. 3 werefully constrained, and the constraint other than the $x$-axis translation of the opposite grip part was applied. Moreover, the load $F$ was defined as the tensile shear direction ( $x$-axis direction) with respect to the joint, and its value was set to $1000 \mathrm{~N}$.

\section{Experimental methodology}

\section{1 joint specimen manufacture}

In the process of manufacturing the joint specimens shown in Fig. 1, the above-mentioned epoxy structural adhesive was used. This adhesive is a two-component room temperature setting type, and is a mixture of the base resin and the hardener at a weight ratio of 1:1. The arithmetic mean roughness $R a$ of the surface of the adherend was adjusted to $2.0 \pm 0.2 \mu \mathrm{m}$, and the surface was cleaned and degreased with an ultrasonic cleaner and acetone. Next, the prepared adhesive was applied and laminated so that the overlapping length was $25 \mathrm{~mm}$, and fixed using a specially designed jig and a vise. After that, it was naturally dried at $25^{\circ} \mathrm{C}$ for 24 hours in a gravity convection oven, and then heated at $80{ }^{\circ} \mathrm{C}$ for 2 hours. It was confirmed that the thickness of the adhesive layer was 0.05 to $0.13 \mathrm{~mm}$ (3M Japan recommended value) after the completion of drying.

\subsection{Tensile shear test}

The joint specimen shown in Fig. 5 (a) was attached to the grip of the precision universal testing machine (Autograph AG-100kNX plus, SHIMADZU Corp.), and the crosshead displacement and load until the joint broke were recorded while applying tensile shear at a displacement speed of $0.3 \mathrm{~mm} / \mathrm{min}$. Fig. 5 (b) shows the joint specimen held by the testing machine. The number of joint specimens was 5 sets or more for each joint.

\section{Results and Discussion}

\subsection{Analytical result}

Fig. 6 shows Mises stress $\sigma_{m}$ on the central surface of the adhesive layer in a three-dimensional distribution based on the FEM analysis results of each joint. Position $x$ and $z$ in Fig. 6 indicate the coordinate values in the longitudinal direction and the width direction of the lapped part, respectively. Also, the ordinate means the value of Mises stress $\sigma_{m}$. From Fig. 6, it can be seen that the stress distribution has relatively symmetry when the fiber direction of the outermost layer of the Qi-CFRPs (the layer closest to the adhesive layer) is the joint longitudinal and transverse directions. On the other hand, as shown in Fig. 6(b) and (c), when the fiber direction of the outermost layer of the Qi-CFRPs is inclined to $45^{\circ}$, the non-uniformity of the stress distribution in the $\mathrm{z}$ direction can be confirmed. In particular, the stress distribution in Fig. 6(b) shows remarkable fluctuations, and the maximum value of Mises stress $\sigma_{m}$ is found to be the highest among the four types. From the above, it was suggested that the laminated structures of the Qi-CFRPs affect the stress distribution of the adhesive layer.

\subsection{Experimental result}

Fig. 7 is an example of the load-displacement diagrams obtained from the tensile shear tests of each joint. It can be seen that the load and displacement of Laminate A/A6063 greatly exceed those of other joints. It is considered that this is because the adhesive layer stress distribution of Laminate A/A6063 is more uniform than that of other joints. The flexural modulus of Laminate A to D are 44.78, 16.70, 27.28 , and $10.31 \mathrm{GPa}$, respectively. Due to bending deformation under tensile shear load is suppressed, laminate $\mathrm{A}$ has the highest flexural modulus among the four types. It is presumed that the fracture load of the joint increases because the peeling of the adhesive layer.

Fig. 8 shows the arithmetic mean values of tensile shear strength and crosshead displacement of each joint. The tensile shear strength of the first ordinate is the fracture load value of the joint divided by the bonding area of 625 


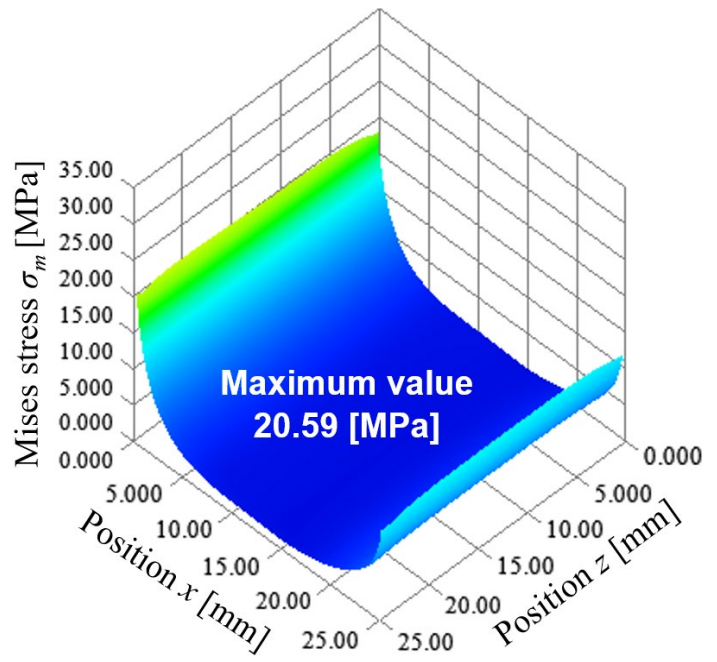

(a) Laminate $\mathrm{A} / \mathrm{A} 6063$

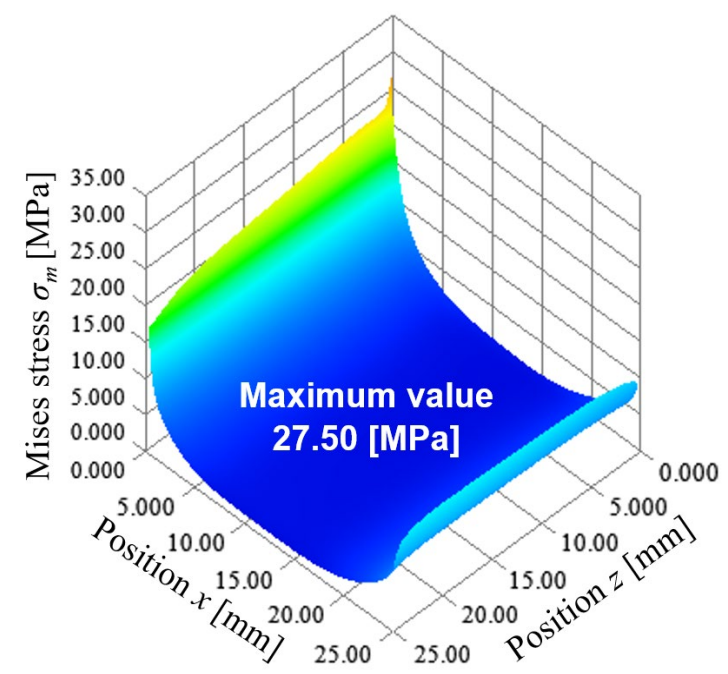

(c) Laminate C/A6063

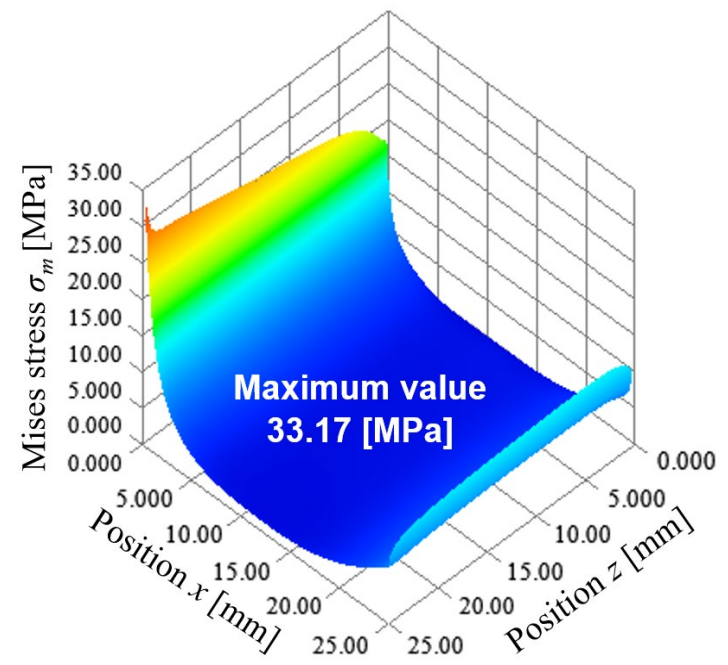

(b) Laminate B/A6063

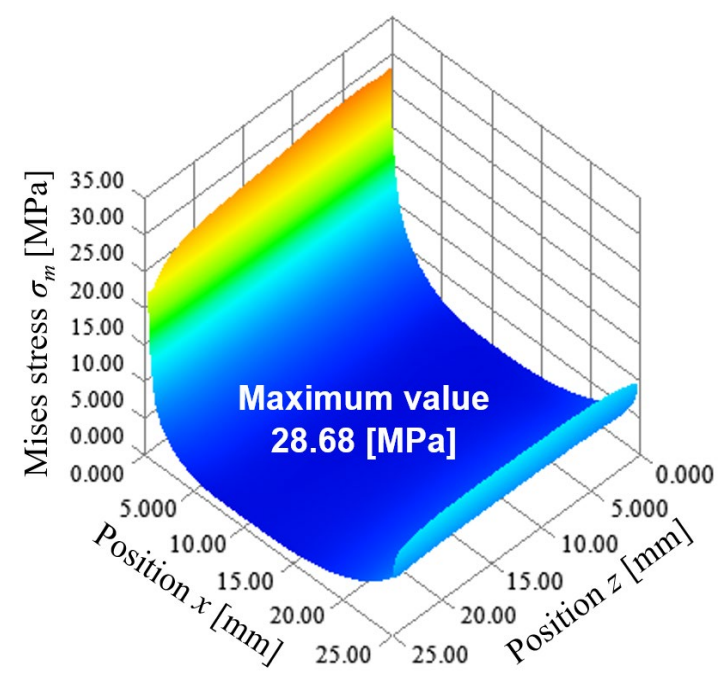

(d) Laminate D/A6063

Fig. 6. Stress distribution at central plane of adhesive layer

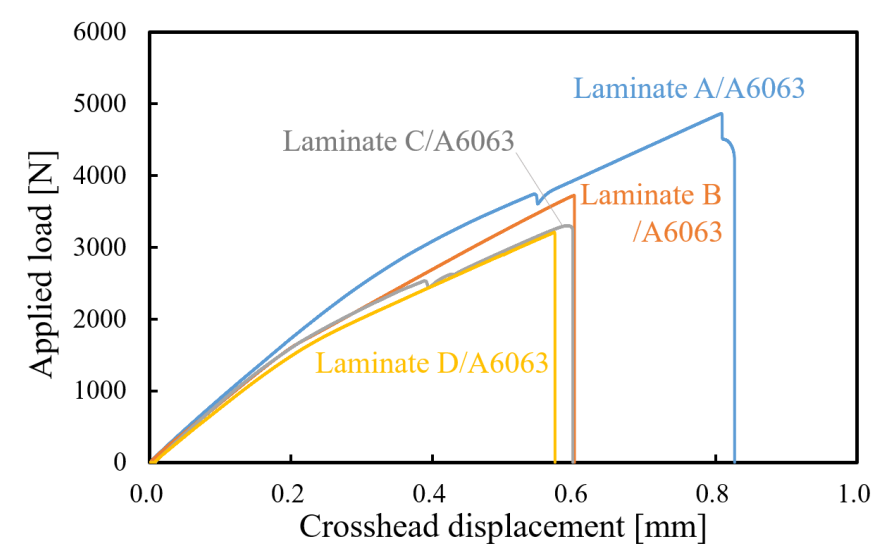

Fig. 7. Applied load - crosshead displacement

diagram of each joint

$\mathrm{mm}^{2}$, and the second ordinate is the crosshead displacement when the joint is broken. The tensile shear strength of each joint increases as the fiber direction of the outermost layer of the Qi-CFRPs approaches the longitudinal direction of

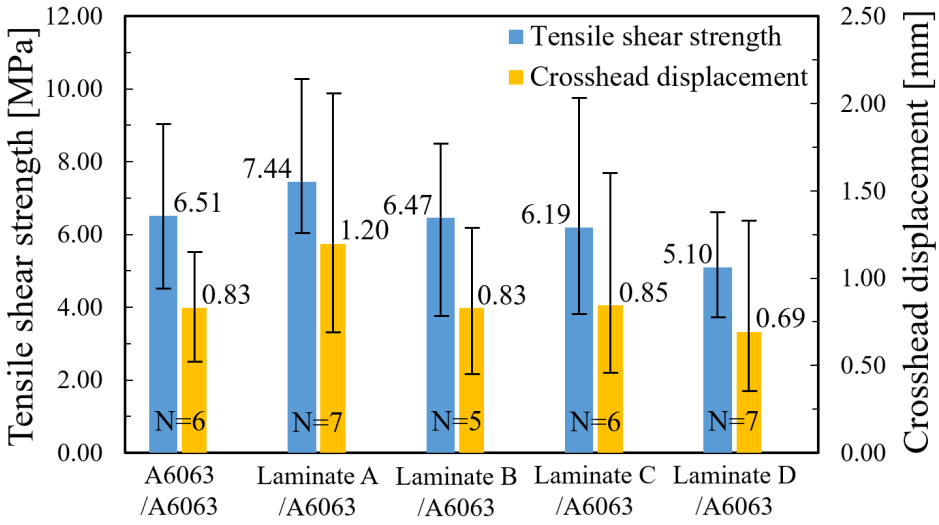

Fig. 8. Averaged values of tensile shear strength and crosshead displacement

the joint, and has a magnitude relationship of Laminate $\mathrm{A}>$ $\mathrm{B}>\mathrm{C}>\mathrm{D}$. Comparing the strengths including the error bars, we can see the correlation with the flexural modulus of each laminate. Furthermore, a similar tendency was 


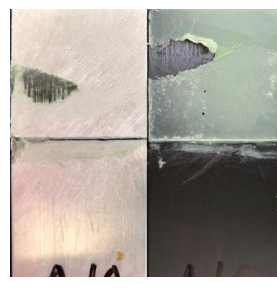

(a) Laminate A/A6063

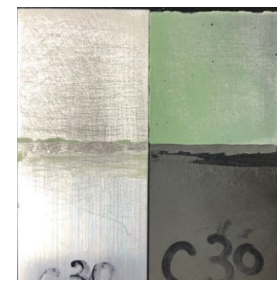

(c) Laminate C/A6063

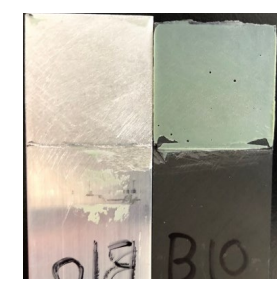

(b) Laminate B/A6063

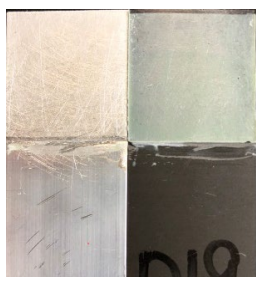

(d) Laminate D/A6063
Fig. 9. Fracture surface at overlapped part

confirmed for crosshead displacement.

Fig. 9 shows the fracture surface of the overlapping part. Interfacial fracture is dominant in all joints except Laminate $\mathrm{A} / \mathrm{A} 6063$, and it is inferred from the stress distribution in Fig. 6 that the end of the overlapped part ( $x=0$ side) is the fracture origin. However, in the case ofLaminate A/A6063, material fracture was observed, which is a partial peeling of the CFRP adherend. In this fracture mode, the tensile shear strength is equal to the peel strength of CFRP, so it is considered that the tensile shear strength is higher than that of other joints in which interface fracture is dominant.

\section{Conclusions}

In this study, we have investigated the tensile shear strength characteristics of the adhesively bonded single-lap joints made of the Qi-CFRPs and aluminum alloy. The results obtained so far are as follows.

1) From the FEM analysis results, it was suggested that the laminated structures of the Qi-CFRPs affect the stress distribution of the adhesive layer.

2) It was found that the tensile shear strength of each joint increases as the fiber direction of the outermost layer of the Qi-CFRPs approaches the longitudinal direction of the joint, and the magnitude relationship is correlated with that of the flexural modulus of each laminate.

\section{Acknowledgment}

We gratefully acknowledge the work of past members of our laboratory and manufacturing center first group belonging to National Institute of Technology, Tokyo College.

\section{References}

(1) J.J.M. Machado, P.D.P. Nunes, E.A.S. Marqus, Lucas F.M. da Silva : "Numerical study of similar and dissimilar single lap joints under quasi-static and impact conditions", International Journal of Adhesion and Adhesives, Vol.96, pp.1-10, 2020

(2) Jairaja R, G Narayana Naik, "Single and dual adhesive bond strength analysis of single lap joint between dissimilar adherends", International Journal of Adhesion and Adhesives, Vol.92, pp.142-153, 2019

(3) Elena M. Moya-Sanza, Inés Ivañezb, Shirley K. Garcia-Castillob, "Effect of the geometry in the strength of single-lap adhesive joints of composite laminates under uniaxial tensile load", International Journal of Adhesion and Adhesives, Vol.72, pp.23-29, 2017

(4) Keita SUNADA, Nobuharu YOKOYAMA, Kazuhiro KUSUKAWA, "Effect of stacking sequences on strength characteristics of adhesively bonded Single-lap joints between Aluminum alloy and CFRP laminates", Proceedings of The 58th Symposium on THE ADHESION SOCIETY OF JAPAN, P47A, 2020

(5) Naoya ASHIHARA, Jyo SHIMURA, Mutsumi MIYAGAWA, Shigeru KUROSAKI, "Bending Strength Properties of Adhesively Bonded Single-lap Joints Composed of Quasi-isotropic CFRP Adherends", Proceedings of Material and Mechanics 2017 Conference on The Japan Society of Mechanical Engineers, OS1404, 2017

(6) Tsuyoshi YANAGITA, Hirotaka TSUTSUMI, Shigeru KUROSAKI, Jyo SHIMURA, "Tensile Shear Strength Characteristics for Adhesively Bonded Double-lap Joints Composed of Quasi-isotropic CFRPs and Aluminum Alloy Adherends", Proceedings of The 59th Lecture for Graduate Research Presentation on The Japan Society of Mechanical Engineers Kanto Branch, 1103, 2020

(7) Akane MURANAKA, Takuo SUZUKI, Shigeru KUROSAKI, Jyo SHIMURA, "Compressive Shear Strength Characteristics for Adhesively Bonded Single-lap Joints Composed of Quasi-isotropic CFRPs and Aluminum Alloy Adherends", Proceedings of The 58th Lecture for Graduate Research Presentation on The Japan Society of Mechanical Engineers Kanto Branch, 909, 2019 